Research Article

\title{
Iterative Method for Predicting Uneven Bridge Approach Settlement (BAS) Caused by Vehicle Loads
}

\author{
Hong-lei Sun $\mathbb{D}^{1},{ }^{1}$ An-hua Chen $\left(\mathbb{D},{ }^{2}\right.$ Li Shi $\mathbb{D}^{1},{ }^{1}$ and Yuan-qiang Cai ${ }^{1,3}$ \\ ${ }^{1}$ Institute of Geotechnical Engineering, Zhejiang University of Technology, Hangzhou, Zhejiang 310023, China \\ ${ }^{2}$ Institute of Disaster Prevention Engineering, Zhejiang University, Hangzhou, Zhejiang 310058, China \\ ${ }^{3}$ Research Center of Coastal and Urban Geotechnical Engineering, Zhejiang University, Hangzhou, Zhejiang 310058, China
}

Correspondence should be addressed to Li Shi; lishi@zjut.edu.cn

Received 20 December 2019; Revised 20 April 2020; Accepted 4 May 2020; Published 19 May 2020

Academic Editor: Enrico Conte

Copyright $\odot 2020$ Hong-lei Sun et al. This is an open access article distributed under the Creative Commons Attribution License, which permits unrestricted use, distribution, and reproduction in any medium, provided the original work is properly cited.

With the development of the transportation, the bridge approach settlement (BAS) received great attention which can result in structure deterioration of the bridge and road, costly maintenance, and hazardous driving conditions. Therefore, accurate prediction of BAS is important. In this paper, a methodology using the iterative procedure is presented to predict the long-term BAS. In this method, the dynamic deviator stress is obtained by a 3D finite element road model and the settlement is calculated by an empirical model with the dynamic deviator stress. Then, the settlement is used as the excitation of the vehicle model for updating the load in the 3D road model. After several iterative calculations, the long-term BAS can be obtained. The comparison between the iterative method and the empirical method is presented. Also the parametric study of the empirical equation is performed. A simplified equation considering the iterative procedure is proposed for engineering practice. Computed results showed that the permanent settlement predicted by the iterative method is larger than that calculated by the empirical method. Also, the parameters of the empirical equation have great effects on the settlement prediction. The applicability of the new empirical equation is also proved.

\section{Introduction}

Recent years have seen the rapid development of modern transportation. The weight and speed of vehicles have greatly increased, resulting in a significant increase in the dynamic effect of vehicles on the road and also on the bridge-embankment transition zone which will magnify the BAS. A "dip" will form at the bridge-embankment transition zone due to this settlement, which will make the vehicle bumpy extremely. It has a significant impact on the safety and comfort of the drivers and passengers. Also, the BAS will lead to costly long-term road maintenance. Therefore, more investigations for predicting the BAS are required to quantitatively characterize the settlement.

The causes of BAS have already been studied in [1-6], which can contribute to finding methods to slow the development of the BAS. To study the impact of the BAS on passing vehicles, the dynamic response of vehicles influenced by the BAS has also been researched by many scholars [7-10]. However, the research on the prediction of the BAS is rather limited.

There have been many studies on the prediction of road settlement. Some researchers used constitutive models [11-13] to calculate permanent deformation of the road, and the empirical models were also used for predicting the cumulative plastic strain. However, since the constitutive model simulates soil behavior in each load cycle, it costs huge amount of calculation when predicting settlements under large number of cyclic traffic loads which makes it not applicable in engineering practice. Empirical models, compared with constitutive models, can fully consider the characteristics of cyclic loads and predict the long-term settlement more accurately. Among all the empirical models, a power equation, proposed by Monismith et al. [14], was always considered and most commonly used by other researchers. They established this model through analyzing the 
results of the repeated-load triaxial compression tests for obtaining the relationship between cumulative plastic strain and the number of load cycles. However, this model could not quantify the major influence factors such as the soil type, soil properties, and stress state. Li and Selig [15] developed this model by proposing a procedure to consider the effect of the deviator stress and soil static strength. Thereafter, they found the developed model was also qualified for predicting the settlement of cohesive soils induced by the train load [16]. A new empirical equation that considered the effect of initial static deviator stress was presented by Chai and Miura [17]. It was proved to be suitable for calculating the permanent settlement of the road on the soft subsoil by considering the traffic load as a static load. Ren et al. [18] proposed a novel empirical model based on analogy analysis of the Hardin-Drnevich model and the Monismith model. This model was used for analyzing the cumulative plastic deformation of soft marine clay under long-term traffic loads.

However, the empirical equation can only simulate the long-term response of the soil. In fact, the BAS is a process of coupling short-term response with long-term response [19]: the interaction force between the vehicle and the road increases as the settlement of the bridge-road transition zone increases. Also, the deviator stress increases due to the amplification of the interaction force which will contribute to the further increase of settlement as a consequence. However, most existing research studies on differential settlement at the bridge approach zone have not considered this process. Wang and Markine [20] presented an iterative methodology to overcome this problem. They combined a 3D finite element model with the empirical model and designed an iterative procedure. The BAS can be predicted more precisely by using this method. Similar iterative approaches have also been proposed for calculating the traincaused track permanent settlement $[19,21,22]$. However, the simulation of road differential settlement is different from that of the track permanent settlement on the aspect of embankment condition, load transfer path, and dynamic response. Also, the vehicle excitation at the road differential settlement is the tire-road contact force while that at the track permanent settlement is the wheel-rail contact force. Therefore, it is necessary to put forward a specific iterative method for predicting the BAS.

In this paper, an iterative methodology was presented for calculating the long-term bridge approach settlement. This method combines the finite element vehicle-road model and an empirical model of cumulative plastic strain. A moving point load is applied to the ground surface to represent the vehicle excitation in the $3 \mathrm{D}$ finite element road model. The ground in the $3 \mathrm{D}$ road model is modeled as a single-phase elastic medium. The comparison between the iterative method and the empirical method is presented, and the effect of the parameters in the empirical equation on the permanent settlement prediction is also investigated. In order to simplify the iterative methodology for engineering practice, a new empirical equation is proposed. Also, the applicability of the simplified method is discussed in this research.

\section{Iterative Computation Method}

An iterative computation method for predicting the longterm BAS is shown in this section. The main parts of the method are as follows:

(I) Calculating the deviator stress of the soil using the 3D bridge-road finite element model.

(II) Calculating the primary cumulative plastic deformation of the road caused by a given number of loading cycles with the deviator stress in step I and the empirical model developed by Chai and Miura [17]. Then, the BAS after several loading cycles $(N)$ can be calculated with the cumulative plastic deformation of the road.

(III) Changing the vehicle load by updating the vehicle model. Also, the BAS calculated in step II is used as the excitation of the vehicle model updating.

(IV) Updating the 3D finite element model with the new vehicle load for step and then continuing the next iteration from step I.

It is assumed that the properties and geometry of the vehicle-road model are constant, and the load of each passing vehicle is the same within each iteration step. The iteration process is schematically shown in Figure 1.

\section{Simulation Model for Settlement Prediction}

The simulation model consists of a $2 \mathrm{D}$ vehicle model, a $3 \mathrm{D}$ bridge-road transition zone finite element model, and an empirical model of cumulative plastic strain. The simple schematic of the bridge transition zones is shown in Figure 2. The vehicle model and the bridge-road model are short-term models updating in each iteration step to reflect the current state of the differential settlement. The updated soil deviator stress is used as an input for the empirical model, and detailed descriptions of the three models are presented in Sections 3.1-3.3.

3.1. Vehicle Model. In this paper, the vehicle is modeled as a simple single-axis model [9] to simplify the analysis process as in Figure 3. The vehicle body and the wheel are connected through a suspension system. $k$ and $c$ represent the stiffness and the damp of the suspension spring, respectively.

As Figure 3 shows, there is a "dip" at the bridge-embankment transition zone caused by the differential settlement of the bridge approach. The process of vehicle running from the bridge to the dip is assumed to be a free fall motion. The speed of the vehicle in the vertical direction at the dip is expressed as $v_{y}$. The equation of motion for the vehicle body is written as

$$
M \ddot{u}+c \dot{u}+k u=0 .
$$

Equation (2) can be obtained by dividing equation (1) with $M$ :

$$
\ddot{u}+2 \zeta \omega_{n} \dot{u}+\omega_{n}^{2} u=0,
$$




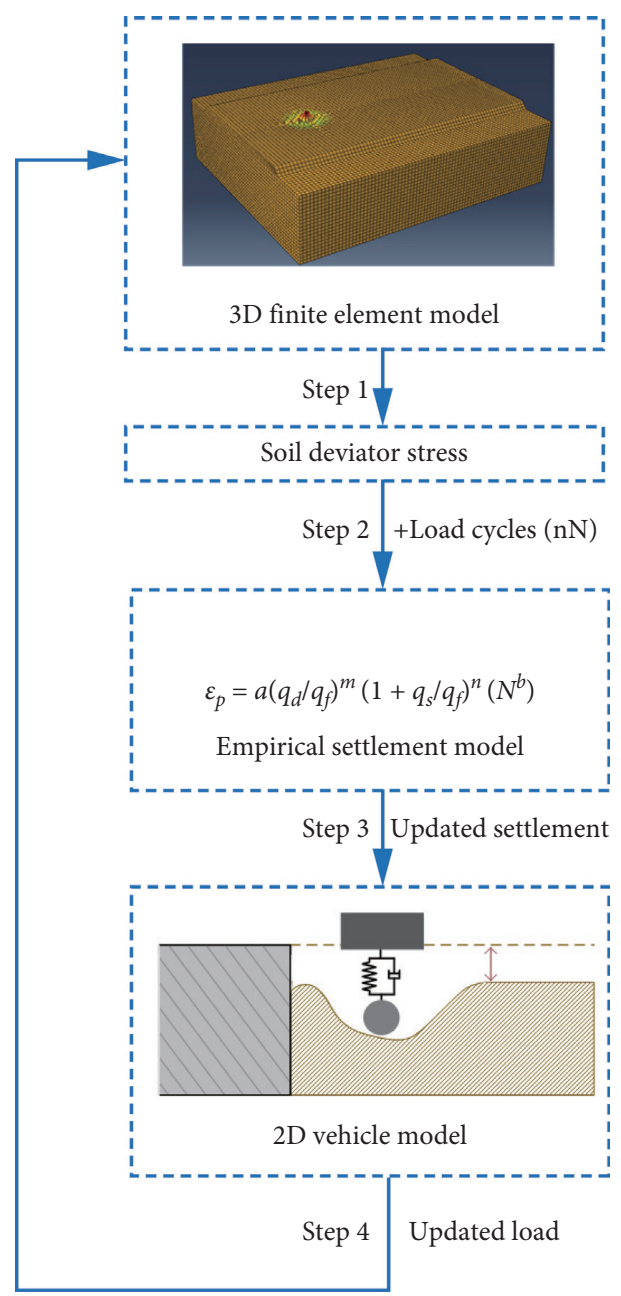

FIGURE 1: Iterative procedure to predict the settlement in bridge transition zones.

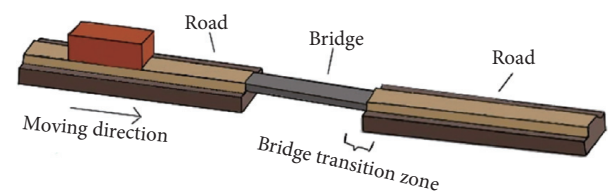

Figure 2: Bridge transition zones.

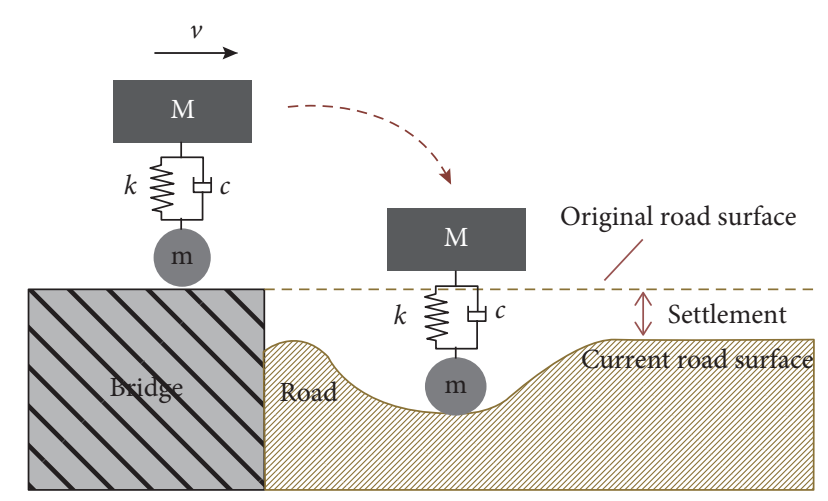

Figure 3: Simplified 2D vehicle model. where $\omega_{n}=\sqrt{k / M}, \zeta=c / 2 M \omega_{n}, M$ denotes the mass of the vehicle body, $u$ denotes the vertical displacement of the vehicle body, and "." and ".." denote the first and second derivative of time, respectively.

The initial condition of the displacement $u$ and speed $\dot{u}$ is

$$
\left\{\begin{array}{l}
u=0, \\
\dot{u}=v_{y} .
\end{array}\right.
$$

The equation of the displacement can be obtained from equations (2) and (3):

$$
u(t)=e^{-\zeta \omega_{n} t}\left[\frac{v_{y}}{\omega_{D}} \sin \omega_{D} t\right],
$$

where $\omega_{D}=\omega_{n} \sqrt{1-\zeta^{2}}$.

Then, the force of the wheel applying on the road $F(t)$ can be calculated by the following equation:

$$
F(t)=u(t) k+G,
$$

where $G$ denotes the gravity of the vehicle.

In the FEM simulation step, $F(t)$ is accounted as the external loads in the 3D bridge-road finite element model.

3.2. Bridge-Road Transition Zone Model. The 3D transition zone FEM model used to calculate the deviator stress was built by ABAQUS. The primary reason for the BAS is considered as the significant change in vertical stiffness [2]. The stiffness of the bridge is much larger than that of the road in the transition zone. The settlement of the bridge can be negligible compared with that of the road after several loading cycles. Therefore, only the road part of the bridgeroad transition zone is simulated to reduce the calculation costs as Figure 4 shows.

The model size is $32 \mathrm{~m}$ (width) $\times 11.4 \mathrm{~m}$ (height) $\times 40 \mathrm{~m}$ (length), and the width of the pavement is $10 \mathrm{~m}$. There are 215360 elements, and the type of the element is C3D8R. The size of all the elements is $0.5 \mathrm{~m}$. The road model is divided into three layers. They are pavement $\left(h_{1}\right)$, subgrade $\left(h_{2}\right)$, and subsoil $\left(h_{3}\right)$, respectively. A nonoscillating point load $F_{n}$ that moves along the positive $z$ axle acts vertically on the surface of the ground. An additional 10 meters of subsoil is added to the bottom to prevent reflected waves from interfering with the calculation area. Also, the four side surfaces of the model are fixed at $x$ and $z$ directions for avoiding the infinite extension of the ground. The surface of the ground is free.

3.3. Empirical Settlement Model. In this paper, the empirical model presented by Chai and Miura [17] is used. For each iteration step, the cumulative plastic strain can be calculated with the dynamic deviator stress through the empirical model:

$$
\varepsilon_{p}=a\left(\frac{q_{d}}{q_{f}}\right)^{m}\left(1+\frac{q_{s}}{q_{f}}\right)^{n}\left(N^{b}\right),
$$

where $\varepsilon_{p}$ denotes the cumulative plastic strain (\%); $q_{s}$ is the initial static deviator stress and $q_{d}$ is the dynamic deviator stress; $q_{f}$ denotes the static failure deviator stress, $q_{f}=2 S_{u}$, 


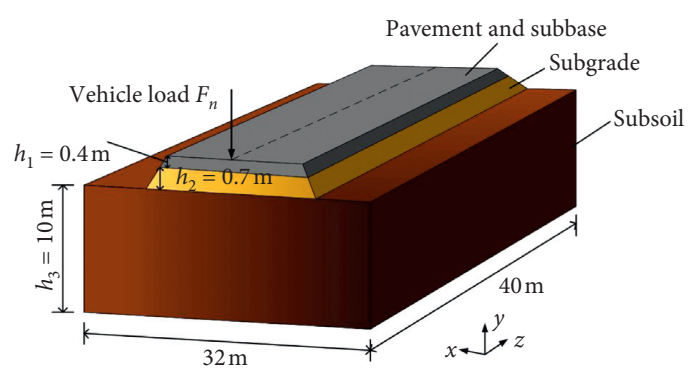

FIgURE 4: 3D bridge-road transition zone model.

$S_{u}$ is the undrained shear strength of soft subsoil, $N$ is the number of load cycles, and $a, b, m$, and $n$ are constants.
The dynamic deviator stress $q_{d}$ induced by the vehicle load can be calculated as

$$
q_{d}=\sqrt{\frac{1}{2}\left[\left(\sigma_{x x}-\sigma_{y y}\right)^{2}+\left(\sigma_{x x}-\sigma_{z z}\right)^{2}+\left(\sigma_{y y}-\sigma_{z z}\right)^{2}+6\left(\tau_{x z}^{2}+\tau_{y z}^{2}+\tau_{x y}^{2}\right)\right]}
$$

where $\sigma_{x x}, \sigma_{y y}, \sigma_{z z}, \tau_{x z}, \tau_{y z}$, and $\tau_{x y}$ can be calculated through the FEM model presented in Section 3.2.

The undrained shear strength of the soil $S_{u}$ can be determined by the empirical equation proposed by Ladd [23].

$$
S_{u}=S \sigma_{v}^{\prime}(\mathrm{OCR})^{m 1}
$$

where $\sigma_{v}^{\prime}$ denotes the effective vertical stress; OCR is the overconsolidation radio; $S$ and $m 1$ are the constants and the suggested values which can be obtained in Ladd [23].

$a, b$, and $m$ are the parameters related to the soil type, soil properties, and stress state, and $n$ is the relation between cumulative plastic strain and initial state deviator stress. We assumed that the magnitude of the plastic strain linearly increases with initial static deviator stress considering the limitation of available test data. So $n=1.0$ is suggested [17]. $S$ controls the magnitude of the static failure deviator stress which plays an essential role in calculation of the cumulative plastic strain. Therefore, it is important to study the influence of parameters $a, b, m$, and $S$ on the BAS.

\section{Numerical Results}

The comparison of the BAS calculated by the iterative method and the traditional empirical model method is presented in this section. The effects of the four parameters in the empirical equation on the BAS are also investigated in this section.

The magnitude of moving point load and the traffic intensity are both recommended by Chai and Miura [17]. The load is set as $100 \mathrm{kN}$, and the traffic intensity is 400 trucks/day. Considering that the service life of the expressway is 15 years [24], the total number of loading cycles is set as 2,200,000 times. Also, the number of load cycles is 100,000 times in each iterative step. The speed of the moving point load is $20 \mathrm{~m} / \mathrm{s}$. The moving distance of the point load is $10 \mathrm{~m}$ which is longer than the length of the bridge-embankment transition zone. Also, the stiffness $k$ is $904 \mathrm{kN} / \mathrm{m}$ and the damp of the suspension $c$ is $44.2 \mathrm{kN} / \mathrm{m}$ according to Liang et.al. [25]. The thickness and Young's modulus of each layer of the FEM model are determined according to the case analysis by Chai and Miura [17], as shown in Table 1. The Rayleigh damping is considered in this model, and the damping ratio is $2 \%$. The Rayleigh damping factors $\alpha$ is 0.0966 and $\beta$ is $4.14 \times 10^{-3}$ for the whole structure.

4.1. Comparisons with Traditional Empirical Model. In this section, the BAS is calculated by the iterative method and the empirical model method, respectively, and the parameters of the empirical equation are shown in Table 2 (Chai and Miura [17]).

The comparison of BAS from 0 to 2,200,000 loading cycles predicted by the two methods is shown in Figure 5. In this simulation model, the drop point is generally at $2.5 \mathrm{~m}$ away from the bridge when the vehicle leaves the bridge for free fall movement. We assume that the force of the wheel applying on the road $F(t)$ reaches its maximum at this position. Therefore, the BAS reaches its maximum value at the same point, and this position $(x=16 \mathrm{~m}, y=11.1 \mathrm{~m}$, and $z=2.5 \mathrm{~m}$ ) is chosen as the observation point to record the BAS calculated by the two methods.

It is observed from Figure 5 that the prediction of the BAS through both methods increases as the loading cycles increases. Also, the growth rate decreases with the increasing loading cycles. However, the increase in speed of the settlement calculated by the iterative method is obviously faster than that predicted by the empirical method. Therefore, the difference between the BAS predicted by the two methods increases as the loading cycle increases. Also, the settlement at 2,200,000 loading cycles calculated by the iterative method is almost three times greater than that calculated by the empirical method.

That is because the load is amplified resulting in the increasing of the dynamic deviator stress field at each iteration step when using the iterative method. Also, the settlement increases with the increasing of the dynamic 
TABLE 1: Thickness and Young's modulus of each layer in road model.

\begin{tabular}{|c|c|c|c|c|c|}
\hline \multicolumn{2}{|c|}{ Pavement and subbase } & \multicolumn{2}{|c|}{ Subgrade } & \multicolumn{2}{|c|}{ Subsoil } \\
\hline Thickness $h_{1}(\mathrm{~m})$ & $\begin{array}{c}\text { Young's modulus } E_{1} \\
(\mathrm{kPa})\end{array}$ & Thickness $h_{2}(\mathrm{~m})$ & $\begin{array}{l}\text { Young's modulus } E_{1} \\
\qquad(\mathrm{kPa})\end{array}$ & Thickness $h_{3}(\mathrm{~m})$ & $\begin{array}{l}\text { Young's modulus } E_{1} \\
(\mathrm{kPa})\end{array}$ \\
\hline 0.4 & 35000 & 0.7 & 30000 & 10 & 3000 \\
\hline
\end{tabular}

TAble 2: Parameters of the empirical equation suggested by Chai and Miura [17].

\begin{tabular}{lccccccc}
\hline Parameter & $a$ & $b$ & $m$ & $n$ & $S$ & $m 1$ & OCR \\
\hline Value & 1.2 & 0.18 & 2.0 & 1.0 & 0.34 & 0.8 & 1.0 \\
\hline
\end{tabular}

deviator stress. As a result, the difference between settlements predicted by the two methods is large. Thus, it is essential to predict the long-term BAS through the iterative method presented in this paper.

4.2. The Influence of $a$. The influences of $a$ on the difference of the BAS calculated by the empirical method and the iterative method are investigated in this section. Three different values of parameter $a=0.9,1.2$, and 1.5 are considered which are all within a reasonable range of $a$ according to $\mathrm{Li}$ and Selig [15]. Only the value of the parameter studied is changed while analyzing the parameter influence. The other parameters remain the same as in Table 2. The subscript $i$ and $e$ represent the empirical method and the iterative method, respectively, in the rest of the paper. $N$ in Figures 6 and 7 represents the number of loading cycles, and the unit of that is 100000 times.

The comparison of BAS for different $a$ between the iterative method and the empirical method is shown in Figure 6. In Figure 7, the final settlements at different loading cycles for different $a$ are presented. From Figures 6 and 7, it can be seen that the settlements calculated by the empirical method and the iterative method increase as $a$ increases. Also, the results of the iterative method are greater than that of the empirical method regardless of the value of $a$.

The iterative method results show that with the increase of $a$, the increment of BAS obviously increases, while that remains almost unchanged in empirical method cases. That results in the greater difference between the settlements predicted by the two methods with a larger value of $a$. Also with the increase of the loading cycles, the growth rate of the iterative method settlement increases as the value of $a$ is increasing. In contrast, the result predicted by the empirical method did not show this trend.

4.3. The Influence of $b$. In this section, the influences of $b$ are investigated by considering three different values of $b$, i.e., $b=0.06,0.18$, and 0.25 , which represent different types of the soil [15].

Figure 8 shows the differences between the settlement prediction calculated by the empirical method and the iterative method for different values of $b$. It can be observed that the settlement predicted by the iterative method in the case of $b=0.25$ is much larger than other cases. The

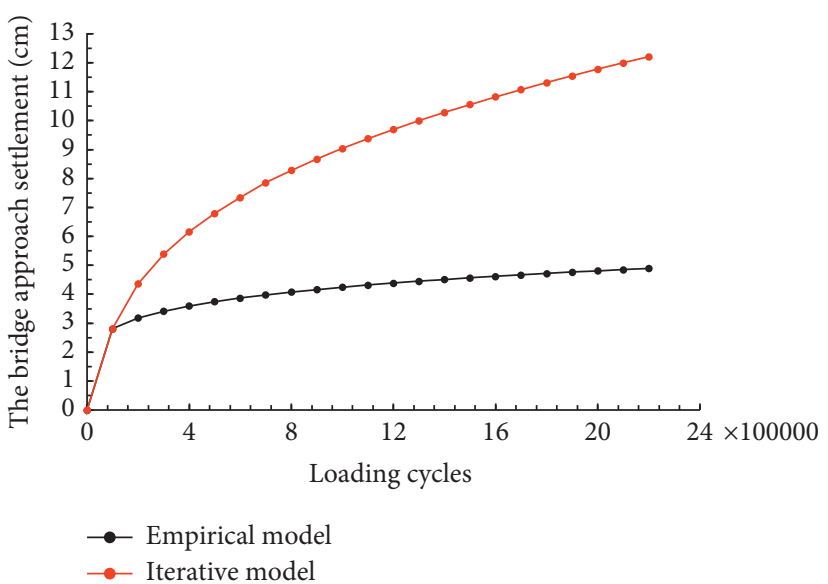

FIGURE 5: The bridge approach settlements at the observation point through two prediction methods.

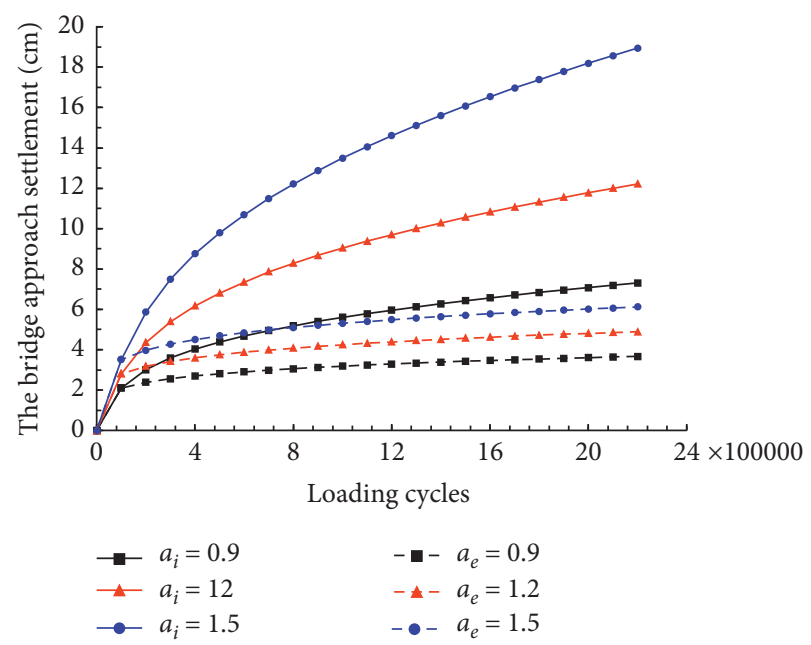

FIgURE 6: The bridge approach settlements at the observation point through two prediction methods for different values of $a$.

settlements of the empirical method and the iterative method both increase with the increasing $b$. As the loading cycle increases, the difference in settlements calculated by the two methods increases.

The settlements at different loading cycles calculated by the iterative method are compared with that calculated by the empirical method and shown in Figure 9. The differences decrease with the value of $b$ decreasing, and the settlements calculated by the two methods are very close with each other when $b=0.06$. It can be clearly seen from Figure 9 that with the increase in the influence of $b$ on the prediction result, both the increase speeds of settlements predicted by the two methods increase. It can be clearly observed in the iterative 


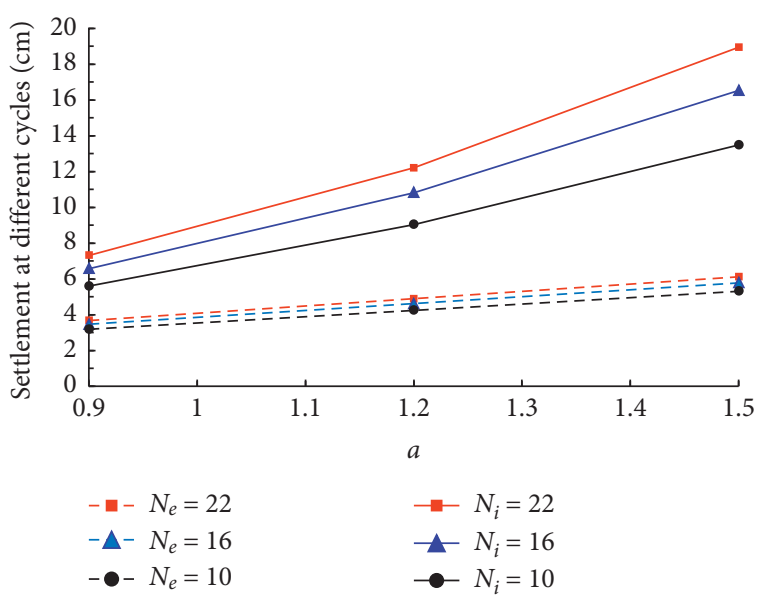

Figure 7: Settlements at different loading cycles at the observation point calculated by two prediction methods.

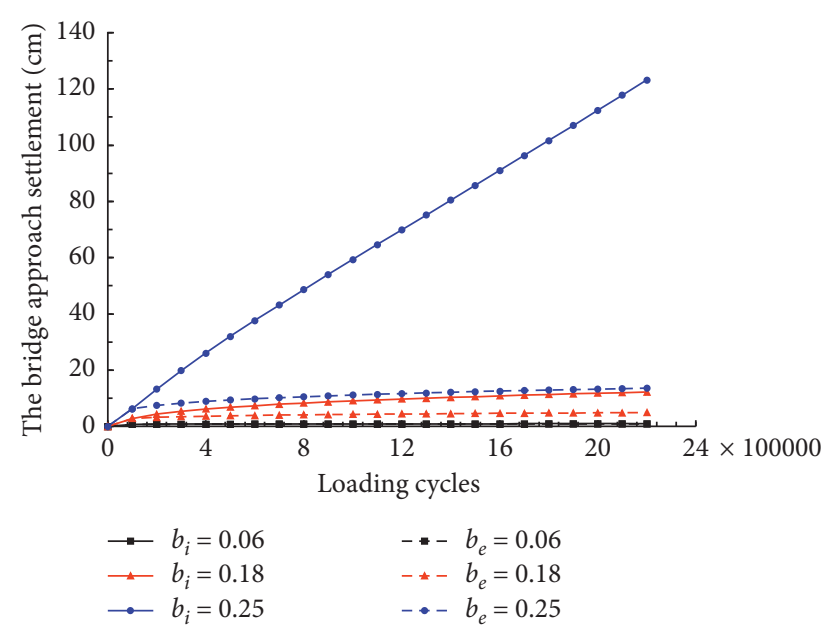

Figure 8: Settlements at the observation point calculated by two prediction methods for different values of $b$.

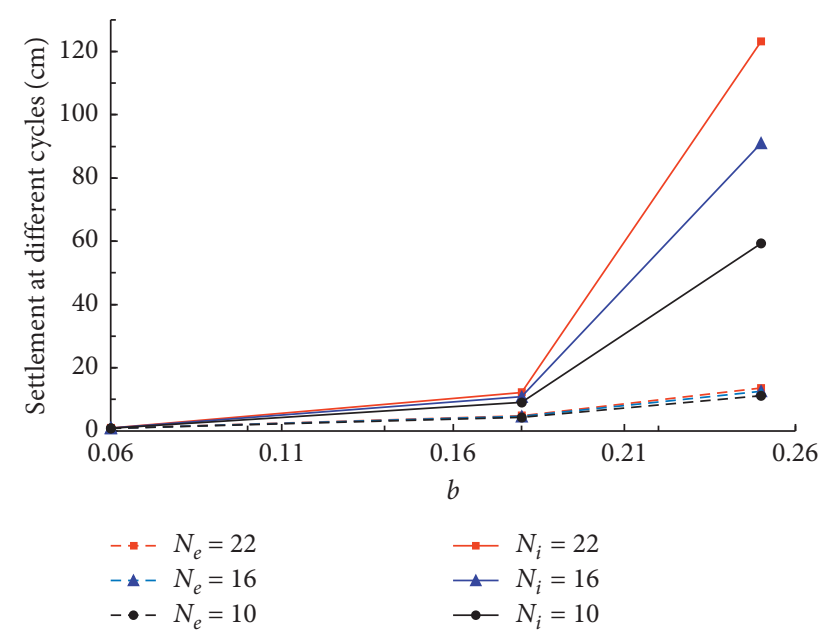

FIGURE 9: Settlements at different loading cycles at the observation point calculated by two prediction methods. method results that the settlements at different loading cycles are close when the value of $b$ is small (i.e., $b=0.06$ and $b=0.18$ ). However, the effect of the loading cycles on the settlement is larger as the value of $b$ is large (i.e., $b=0.25$ ). Parameter $b$ which is determined by the soil type controls the increment rate of the plastic strain with the number of repeated load applications [17]. A higher value of $b$ represents soil with higher clay content and plasticity which leads to a larger difference of prediction results and a larger BAS.

4.4. The Influence of $m$. In this section, a parametric study is conducted for three different values of $m$, i.e., $m=0.06,0.18$, and 0.25 [15].

The prediction results considering different $m$ are displayed in Figures 10 and 11. With the increase in $m$, the prediction calculated by the iterative method decreases, and the trend of the results predicted by the empirical method is the same as that of the iterative method. It can also be observed that the decrease speeds of settlements calculated by the two methods decrease as $m$ increases. Moreover, the difference among different loading cycles is decreasing with the value of $m$ increasing. Also, with the increasing of the loading cycles, the settlement difference among them is decreasing.

A higher value of $m$ represents the higher degree of softening of soil [23]. Since $q_{d} / q_{f}$ is smaller than 1.0, the BAS decreases with the increase in $m$. Therefore, the lower the degree of softening of soil, the larger the differences of the settlement prediction results calculated by two methods. Also, with the degree of softening of soil decreasing, the BAS increases.

4.5. The Influence of S. In this section, the influences of $S$ on the difference of the BAS calculated by the empirical method and the iterative method are investigated by considering three different values of $S$, i.e., $S=0.25,0.30$, and 0.34 .

Figure 12 shows the settlements predicted by two methods for different values of $S$. From the comparison, it can be seen that the results calculated by the iterative method are larger than that predicted by the empirical method. Also, with the decrease in the parameter $S$, both BASs calculated by the two methods increase. That is because $S$ is proportional to the static failure deviator stress. And, the static failure deviator stress is inversely proportional to the cumulative plastic strain in the empirical method. Therefore, $S$ is inversely proportional to the results of BAS.

In Figure 13, as parameter $S$ is increasing, the decrease speeds of long-term settlements calculated by two methods become slower. And, the difference of the results predicted by the two methods decreases. Also, the difference of settlements after different loading cycles decreases with the value of $S$ increasing. The difference among different loading cycles in the empirical method is smaller than that in the iterative method. The greater the number of the loading cycles, the larger the effect of parameter $S$ on the prediction results.

The organic clays and silts have a higher value of $S$ than inorganic clays, and $S$ increases with the increasing plastic 


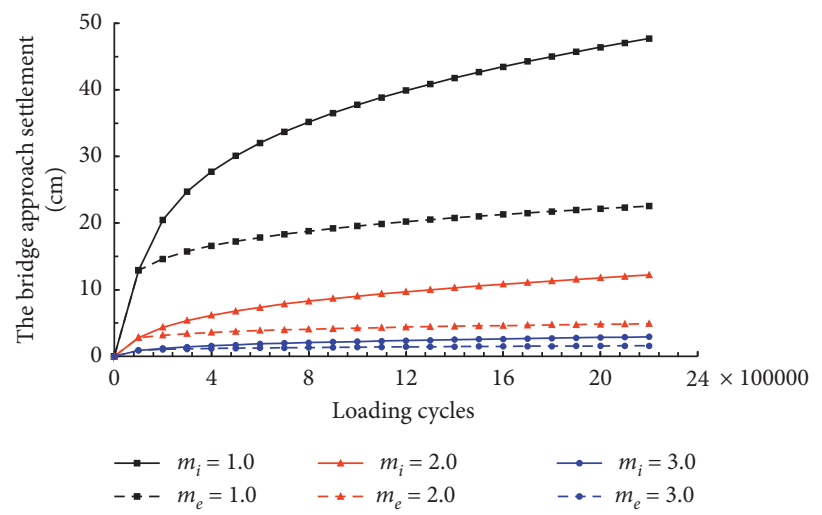

FIgURE 10: Settlements at the observation point calculated by two prediction methods for different values of $m$.

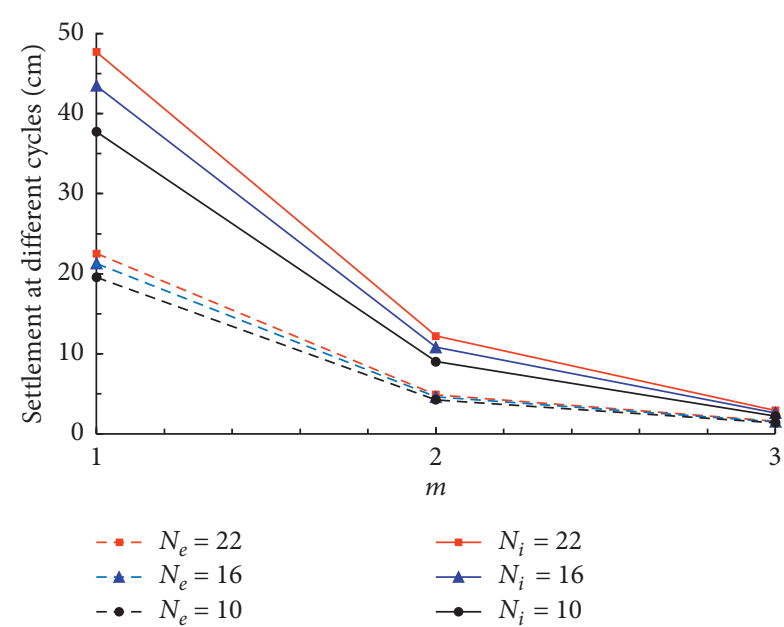

FIGURE 11: Settlements at different loading cycles at the observation point calculated by two prediction methods.

index of the soil for inorganic clays [23]. Therefore, a larger difference of the results predicted by two methods is shown for inorganic clays. The BAS of inorganic clay predicted by two methods is larger than that of organic clays and silts.

\section{New Proposed Predicting Equation}

Since the prediction process of the iterative method is too complicated to be applied to engineering practice, an empirical equation based on Chai and Miura [17] considering the iteration procedure is proposed. Four amplification factors $A, B, M$, and $Q_{f}$ related to $a, b, m$, and $S$, respectively, are added to the original equation, which can be determined in Table 3.

In Table $3, R^{2}$ is the indicator of the fitting degree of the trend line. The reliability of the fitting curve is the highest when $R^{2}$ is equal to $1 . \zeta$ is the reference multiple, and $\zeta=$ $U_{i}^{*} / U_{e}^{*}=2.5$ in this paper. $U_{i}^{*}$ denotes the settlement after 2,200,000 loading cycles predicted by the iterative method while $U_{e}^{*}$ is that predicted by the empirical method. They are both in the situation of $a=1.2, b=0.18, m=2.0$, and $S=0.34$.

Then, the new prediction equation can be proposed:

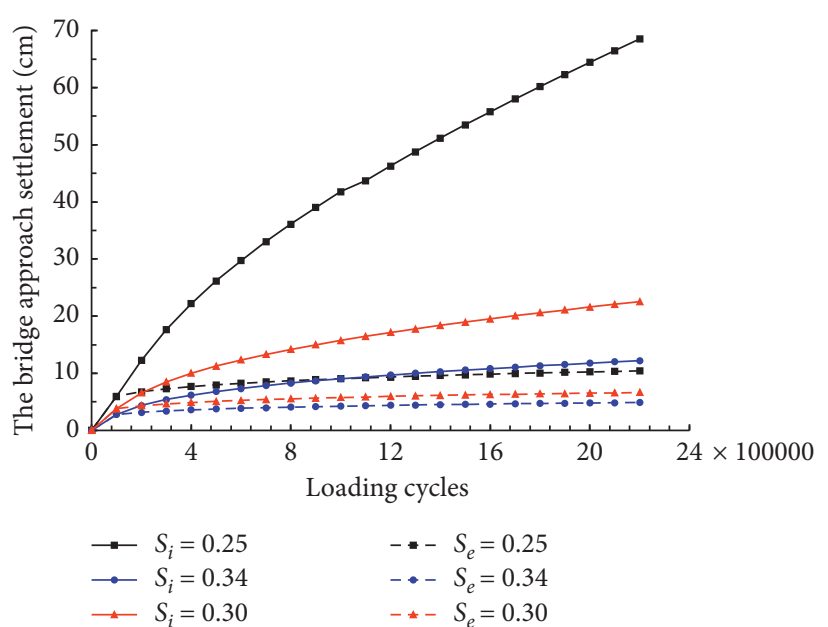

Figure 12: Settlements at the observation point calculated by two prediction methods for different values of $S$.

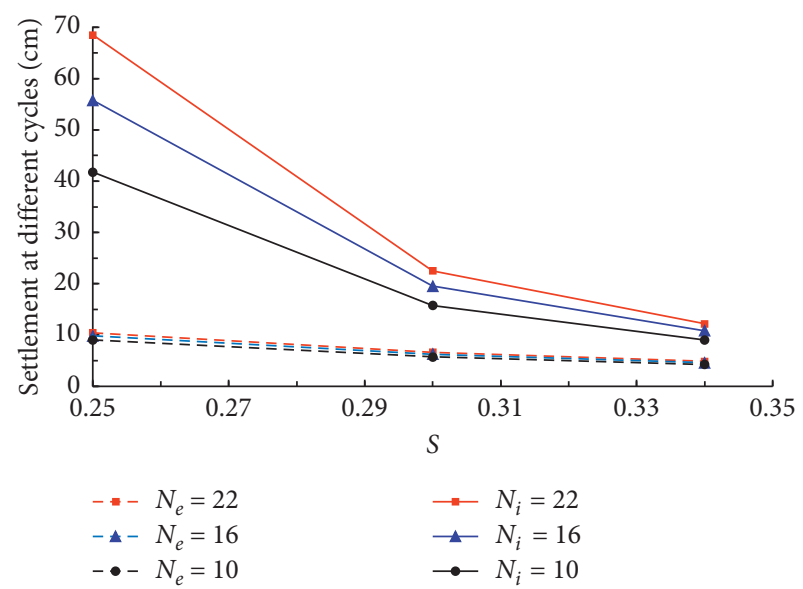

FIgURE 13: Settlements at different loading cycles at the observation point calculated by two prediction methods.

$$
\varepsilon_{p}=\zeta \times A \times B \times M \times Q_{f} \times\left[a\left(\frac{q_{d}}{q_{f}}\right)^{m}\left(1+\frac{q_{s}}{q_{f}}\right)^{n}\left(N^{b}\right)\right],
$$


TABLE 3: The fitting of the amplification factors.

\begin{tabular}{|c|c|c|c|c|}
\hline Amplification factors & Value of parameters $(a, b, m, S)$ & $U_{i}(\mathrm{~cm})$ & $U_{e}(\mathrm{~cm})$ & $U_{i} / U_{e} \zeta$ \\
\hline \multirow{4}{*}{$A$} & 0.9 & 7.308 & 3.669 & 0.798 \\
\hline & 1.2 & 12.212 & 4.892 & 1 \\
\hline & 1.5 & 18.946 & 6.115 & 1.241 \\
\hline & & $0.13, R^{2}=$ & & \\
\hline \multirow{4}{*}{$B$} & 0.06 & 0.933 & 0.848 & 0.441 \\
\hline & 0.18 & 12.212 & 4.892 & 1 \\
\hline & 0.25 & 123.240 & 13.598 & 3.631 \\
\hline & \multicolumn{4}{|c|}{$B=882.88 b^{3}-259.32 b^{2}+25.58 b-0.35, R^{2}=1$} \\
\hline \multirow{4}{*}{$M$} & 1.0 & 47.710 & 22.545 & 0.848 \\
\hline & 2.0 & 12.212 & 4.892 & 1 \\
\hline & 3.0 & 2.925 & 1.586 & 0.739 \\
\hline & \multicolumn{4}{|c|}{$M=-0.21 m^{2}+0.77 m+0.28, R^{2}=1$} \\
\hline \multirow{4}{*}{$Q_{f}$} & 0.25 & 68.524 & 10.429 & 2.632 \\
\hline & 0.3 & 22.532 & 6.639 & 1.360 \\
\hline & 0.34 & 12.212 & 4.892 & 1 \\
\hline & \multicolumn{4}{|c|}{$Q_{f}=0.03 S^{-3.18}, R^{2}=0.9899$} \\
\hline
\end{tabular}

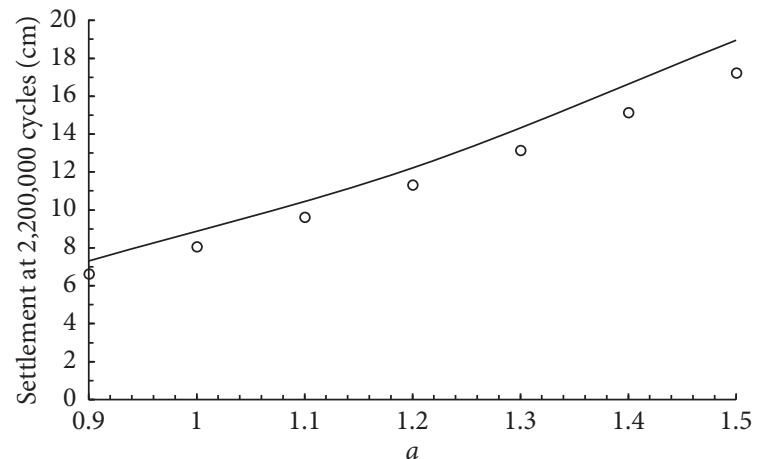

Iterative method

- Simplified method

(a)

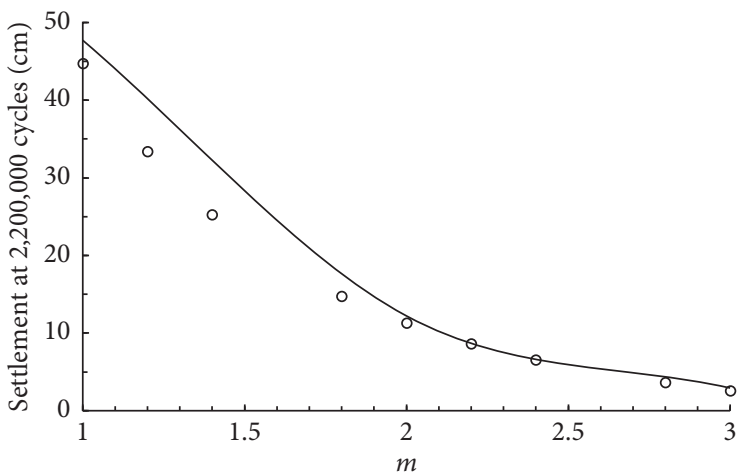

- Iterative method

- Simplified method

(c)

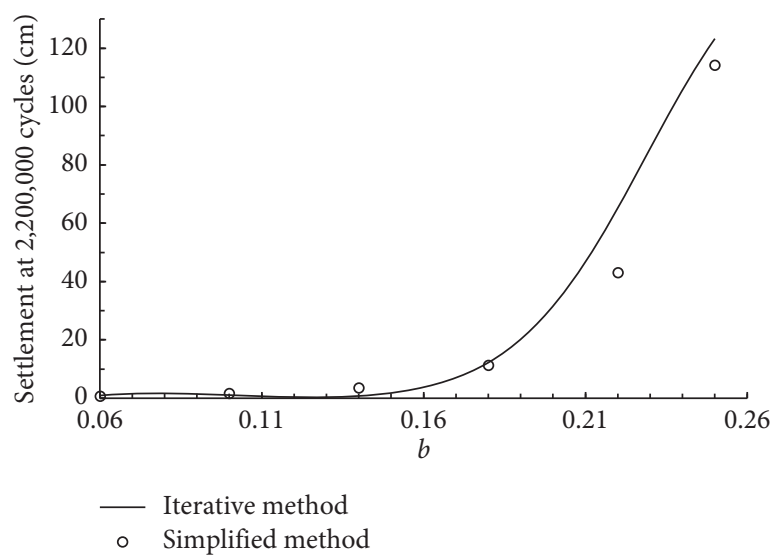

(b)

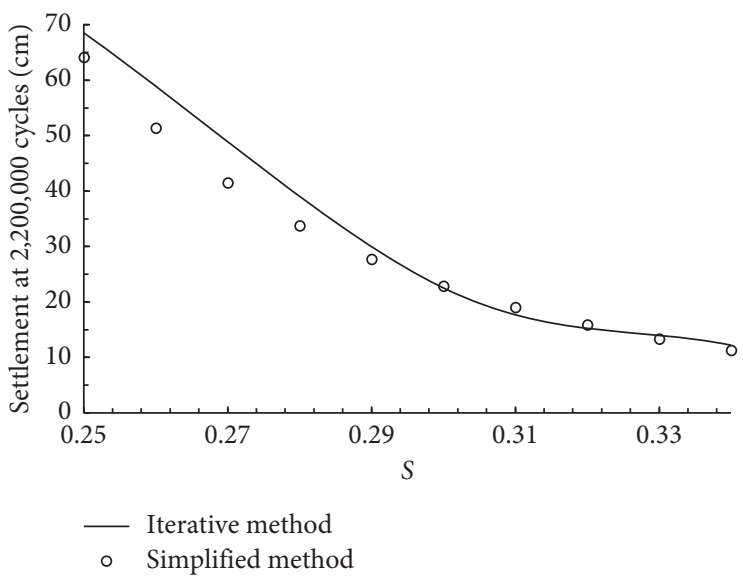

(d)

Figure 14: Comparison of settlements at 2200,000 loading cycles predicted by the iterative method and the simplified method. (a) Settlements at 2200,000 loading cycles for different values of $a$. (b) Settlements at 2200,000 loading cycles for different values of $b$. (c) Settlements at 2200,000 loading cycles for different values of $m$. (d) Settlements at 2200,000 loading cycles for different values of $S$. 
in which the amplification factors are given as

$$
\left\{\begin{array}{l}
A=0.74 a+0.13 \\
B=882.88 b^{3}-259.32 b^{2}+25.58 b-0.35 \\
M=-0.21 m^{2}+0.77 m+0.28 \\
Q_{f}=0.03 S^{-3.18}
\end{array}\right.
$$

The comparisons of BAS at 2,200,000 cycles calculated by the iterative method and the simplified method are presented in Figure 14 to verify the applicability of the simplified method.

The prediction results calculated by the simplified method show good agreement with the iterative ones for different value of parameters. Also, the root mean square errors (RMSE) of the simplified method for $a, b, m$, and $S$ are $1.12,9.28,3.54$, and 4.09, respectively. That means the error caused by the simplification related to $b$ is the largest, and the error caused by the simplification related to $a$ is the smallest in the simplified method. It also can be observed that the error increases with the value of $a$ and $b$ increasing while the error decreases as the value of $m$ increases. The larger error appears in the range of $S=0.25-0.29$ compared to the error appearing in the other range of $S$.

\section{Conclusions}

In this paper, an iterative methodology for predicting the long-term BAS is presented. This methodology is based on a 3D finite element model and an empirical settlement model. The differences between the results predicted by the iterative method and the empirical model method are investigated. Also, the effects of four parameters in the empirical equation on the prediction results are studied. A new equation for predicting the long-term BAS is proposed which can be used for planning of the maintenance procedures. Based on the derivation and numerical examples presented above, the following conclusions can be drawn:

(1) The difference of the settlements predicted by the empirical method and the iterative method is large. With the increasing of the loading cycles, both the settlements and the difference of results between two predicted methods increase, and the prediction results of the iterative method are obviously larger than that of the empirical method.

(2) The order of the effect of the four parameters on the difference of the result between the two methods is $b>S>m>a$. Also, the soil with higher clay content and plasticity shows a larger difference of BAS predicted by the two methods. For the organic clays and silts, the difference between two methods is smaller than that of inorganic clays.

(3) A new prediction equation is proposed by simplifying the iterative method and developing the empirical equation presented by Chai and Miura [17] which considers the iteration procedure in the longterm BAS induced by the vehicle load.
Although a more accurate BAS can be predicted by the iterative method in this study, it has several limitations. A simple single-axis vehicle model is applied for simplification, and considering the expense of the calculations, only one observation point was picked for analyzing. Therefore, a complex vehicle model considering the contact between tires and the road and more observation points are suggested for future researches. The field tests will also be done as part of a follow on this study.

\section{Data Availability}

The data used to support the findings of this study will be made available on request.

\section{Conflicts of Interest}

The authors declare that there are no conflicts of interest regarding the publication of this paper.

\section{Acknowledgments}

This work was supported by the National Key R\&D Program of China (Grant no. 2016YFC0800200), the Projects of International Cooperation and Exchanges NSFC (Grant no. 51620105008), the Fundamental Research Funds for the Provincial Universities of Zhejiang (Grant No. RFB2019006), the National Science Foundation for Young Scientists of China (Grant no. 51608482), and the National Natural Science Foundation of China (Grant no. 51478424).

\section{References}

[1] D. J. White, M. M. Mekkawy, S. Sritharan, and M. T. Suleiman, "“Underlying” causes for settlement of bridge approach pavement systems," Journal of Performance of Constructed Facilities, vol. 21, no. 4, pp. 273-282, 2007.

[2] D. S. Timothy and T. W. Stephen, "Root cause of differential movement at bridge transition zones," Journal of Rail and Rapid Transit, vol. 230, no. 4, pp. 1257-1269, 2016.

[3] N. Abuhejleh, D. Hanneman, D. J. White, T. Wang, and I. Ksouri, "Flowfill and MSE bridge approaches: performance, cost, and recommendations for improvements," Rep. No. CDOT-DTD-R-2006-2, Final Rep., Colorado Department of Transportation, Denver, CO, USA, 2006.

[4] A. Ardani, "Bridge approach settlement," Rep. No. CDOTDTPR-87-06, Colorado Department of Transportation, Denver, CO, USA, 1987.

[5] J. L. Briaud, R. W. James, and S. B. Hoffman, Settlement of Bridge Approaches (The Bump at the End of the Bridge), Transportation Research Board, Washington, DC, USA, 1997.

[6] L. F. Greimann, P. S. Yang, and A. M. Wolde-Tinsae, "Nonlinear analysis of integral abutment bridges," Journal of Structural Engineering, vol. 112, no. 10, pp. 2263-2280, 1986.

[7] X. Shi, C. S. Cai, and S. Chen, "Vehicle induced dynamic behavior of short-span slab bridges considering effect of approach slab condition," Journal of Bridge Engineering, vol. 13, no. 1, pp. 83-92, 2008.

[8] Y. Ding, X. Xie, T. K. Au Francis, and J. Huang, "Analysis of dynamic load of vehicle bumping at bridge-head using distributed spring-damper element," China Civil Engineering Journal, vol. 45, no. 12, pp. 127-135, 2012, in Chinese. 
[9] J. Fan, G. Cao, J. Hu, and B. Liao, "Dynamic analysis of vehicle-bridge interaction considering the action of jump impacting force," Chinese Journal of Solid Mechanics, vol. 37, no. 6, pp. 553-558, 2016.

[10] M. Bouazara and M. J. Richard, "An optimization method designed to improve 3-D vehicle comfort and road holding capability through the use of active and semi-active suspensions," European Journal of Mechanics-A/Solids, vol. 20, no. 3, pp. 509-520, 2001.

[11] Y. F. Dafalias and F. Yannis, "Bounding surface plasticity. I: mathematical foundation and hypoplasticity," Journal of Engineering Mechanics, vol. 112, no. 9, pp. 966-987, 1986.

[12] J. H. Prevost, "A simple plasticity theory for frictional cohesionless soils," International Journal of Soil Dynamics and Earthquake Engineering, vol. 4, no. 1, pp. 9-17, 1985.

[13] O. C. Zienkiewicz, K. H. Leung, and M. Pastor, "Simple model for transient soil loading in earthquake analysis I. Basic model and its application," International Journal for Numerical and Analytical Methods in Geomechanics, vol. 9, no. 5, pp. 453476, 1985.

[14] C. L. Monismith, N. Ogawa, and C. R. Freeme, Permanent Deformation Characteristics of Subgrade Soils Due to Repeated Loading, Transportation Research Board, Washington, DC, USA, 1975.

[15] D. Li and E. T. Selig, "Cumulative plastic deformation for finegrained subgrade soils," Journal of Geotechnical and Geoenvironmental Engineering, vol. 122, no. 12, pp. 1006-1013, 1996.

[16] D. Li and E. T. Selig, "Method for railroad track foundation design. II: applications," Journal of Geotechnical and Geoenvironmental Engineering, vol. 124, no. 4, pp. 323-329, 1998.

[17] J.-C. Chai and N. Miura, "Traffic-load-induced permanent deformation of road on soft subsoil," Journal of Geotechnical and Geoenvironmental Engineering, vol. 128, no. 11, pp. 907-916, 2002.

[18] X.-W. Ren, Q. Xu, J. Teng, N. Zhao, and L. Lv, “A novel model for the cumulative plastic strain of soft marine clay under long-term low cyclic loads," Ocean Engineering, vol. 149, pp. 194-204, 2018.

[19] S. Yao, S. H. Zhou, H. C. Zhou et al., "Iterative method for predicting uneven settlement caused by high-speed train loads in transition-zone subgrade," Transportation Research Record: Journal of the Transportation Research Board, vol. 2607, no. 1, pp. 7-14, 2017.

[20] H. Y. Wang and V. Markine, "Analysis of the long-term behaviour of track transition zones," in Proceedings of the Third International Conference on Railway Technology: Research, Development and Maintenance, Saxe-Coburg Publications, Sardinia, Italy, April 2016.

[21] H. Wang and V. Markine, "Modelling of the long-term behaviour of transition zones: prediction of track settlement," Engineering Structures, vol. 156, pp. 294-304, 2018.

[22] C. O. Jens, Nielsen, and L. Xin, "Railway track geometry degradation due to differential settlement of ballast/subgrade-numerical prediction by an iterative procedure," Journal of Sound and Vibration, vol. 412, pp. 441-456, 2018.

[23] C. C. Ladd, "Stability evaluation during staged construction," Journal of Geotechnical Engineering, vol. 117, no. 4, pp. 540-615, 1991.

[24] JTG D50-2017, Specifications for Design of Highway Asphalt Pavement.

[25] B. Liang, D. Zhu, and Y. Cai, "Dynamic analysis of the vehiclesubgrade model of a vertical coupled system," Journal of Sound and Vibration, vol. 245, no. 1, pp. 79-92, 2001. 